\title{
Fundamentals of Cognitive Metaphor
}

Gabit K. Hasanov ${ }^{1}$, Akbilek P. Mynbayeva ${ }^{2}$, Gaukhar Zh. Duisenbayeva ${ }^{2}$, Gulmira T. Mukhamejanova ${ }^{2}$, Kamar S. Aldasheva ${ }^{2} \&$ Kalzhan T. Kongyratbay

${ }^{1}$ Makhambet Utemisov West Kazakhstan State University, Uralsk, Kazakhstan.

${ }^{2}$ Kazakh National Pedagogical Univercity Abai, Almaty, Kazakhstan.

Correspondence: Akbilek P. Mynbayeva, Kazakh National Pedagogical Univercity Abai, Almaty, Kazakhstan, 13 Dostyk ave. Tel: 8-702-250-8462. E-mail: mutlu_8484@mail.ru

Received: December 15, 2014 Accepted: February 25, 2015 Online Published: June 5, 2015

doi:10.5539/ass.v11n18p82 URL: http://dx.doi.org/10.5539/ass.v11n18p82

\begin{abstract}
This article focuses on study of fundamentals of cognitive metaphor formation that has only recently started to learn in semantics. In this article scientific opinions about cognitive metaphor are described and it tries to figure out the fundamentals of cognitive metaphor formation. To show the features of fundamentals of cognitive metaphor formation, excerpts from collection of poems by A. Kekilbayev are used.
\end{abstract}

Keywords: cognitive metaphor, cognitive activity, conceptoshere, categorization, lexical meaning, traditional metaphor, author's metaphor, combinatorial relation, linguistic picture of the world, conceptual consciousness, language consciousness, national-cultural space, poetical cognition, cognitive knowledge

\section{Introduction}

Trying to figure out fundamentals of cognitive metaphor formation is a complicated task. It's is affected by all factors on its own way. First of all, people's life experience, broadening of thinking area and relationship with other individuals directly affects to the creation of cognitive metaphor. Categorization, which means dividing things that were received from environment - is the fundament of the formation of cognitive metaphor. Formation of linguistic picture of the world in people's consciousness and it's levels such as: simple image of the world, traditional image of the world, cognitive image of the world and scientific image of the world; all these complex conception ass we categorize.

Author's, binary or cognitive metaphors are the results of linguistic image in people's consciousness. Cognitive metaphors are indicators of world's cognitive image in the language. In this scientific work, we try to explain those complex conceptions and analyze its connection to cognitive metaphor.

\section{The Main Part}

First of all, it is influenced by the concept of category. Category is a cognitive type of person's thoughts. According to E.N.Orazalieva: "It's a special concept that allows to generalize and classify people's experience. Nowadays fundamentals of cognitive category, in addition to the main features, provided by new possibilities and develops with people's cognitive activity and ability to combine multi-faceted forms that describe matter and its action into groups and categories" (Orazalieva, 2007). This process of categorization is a root for concrete, abstract, common and proper nouns. For example:

"Mood is a dog, changeable fog

Doubt is the one that spoils a lot" (Kekilbayuly, 1999).

According to the poet's point of view, the main cognitive unity is conceptoshere. Nowadays cognitologists use this term to describe overall creative activity and worldview of the poet and also researches on linguistic elements are been replaced by this term. The first person who used this term was D.S.Likhachov. Also in cognitive linguistics the term conceptual system is used. According to Z.D.Popova and I.A.Sternin "Conceptoshere is a collection of public concepts, and data bank of thoughts" (Popova and Sternin, 2007). "Conceptual system is an individual's constructive formation of continuously connected information of about the world (thoughts, opinion, knowledge)" (Pavilenis, 1983). Cognitive image of the universe and its various types is understood by conceptoshere, altogether conscious information about linguistic notion is corrected in conceptual system. That's why V.Znakov claims that: "Process of realization (understanding) is an activity when individual 
acknowledges the meaning of the world with the help of both earlier and newly received information" (Znakov, 1991). For example:

$$
\text { "Archeologist admires, }
$$

Like a butcher with a knife;

Richest tomb what he desires,

Cruel years have took the life" (Maslova, 2007).

"Picture of the world" is the main unit in cognitive linguistics, sometimes instead of "image of the universe", the concepts such as: "picture of the world", "form of the universe", "model of the universe" are used. As the "picture of the world" is the main category in cognitive linguistics, it is defined various directions of various schools. Overall, representatives of semantics prove that in child's mind forms only simple image of the world, which later becomes a basis for more complex image. Prominent figures of Russian semantics Z.D.Popova and I.A.Sternin point that, first of all, direct and indirect image of the universe forms first, which leads to the cognitive image of the universe and then to the linguistic image of the universe. They write "cognitive picture of the universe is mental image of objective reality formed in person's or people's cognitive consciousness with the help of perceptive apparatus. Cognitive image of the universe is a collection of consciousness conceptoshere and stereotypes given by the culture" (Popova and Sternin, 2007). Furthermore, they address the issue of "artistic image of the universe" which comes from the "linguistic picture of the universe" that was not discussed before. Also say that its main difference from "linguistic picture of the universe" is that it's formed in consciousness of artists, poets and writers, and can be portrayed by individuals' own ways and tools (Popova and Sternin, 2007). For example, in the poet's work this can be noticed in the following cognitive metaphor:

\section{"If only Creator will shows trickster his mercy,}

The torn world I'll enter with smile on my face" (Kekilbayuly, 1999).

Overall, a human recognize the world through his mother-tongue and starts to perceive the national character relying on it. It is believed that the basis is "national picture of the universe", that's why "linguistic image of the universe" and "national image of the universe" simultaneously forms in child's mind. E.Saphir and B.Worf theorize that people perceive and see the world through the prism of their mother-tongue. V.A.Maslova writes: "Image of the universe is showed through parameters of space, time, number, ethnics and etc. Its formation is influenced by language, traditions, nature and landscape, upbringing, study and other social factors. "Linguistic image of the universe" portrays the national picture of the universe and can be showed in language tools of different linguistic levels" (Maslova, 2007).

Owing to the fact that all information and senses are marked by the words and also stages of consciousness are in different levels, a child perceives a lot and his "linguistic picture of the world" is in more compound level. "Linguistic image of the universe", which is a foundation to our research, goes from simple to complex degree, that's why this is a complicated issue that needs in-depth study. The case of "linguistic image of the universe" is very sophisticated, and in addition, it's known that there are plenty of sciences that fall into cognitology, and due to these objective reasons, there are many definitions depending on each science's goals.

A.Islam who devoted his researches to the issue of "linguistic picture of the world" in Kazakh linguistics, states that this category is build on the foundation of pure national cognition. About "image of the universe" he writes: "as the "linguistic picture of the world" we understand the knowledge system that was compiled on the basis of collective national-cultural experience common to national and socio-cultural representatives" (Islam, 2004).

It's unquestionable that to consider individual and subjective image of the universe as the foundation of speaking and thinking activities has already paid off. For example, in the poems of Abish:

"If make it repressed, even oak gonna die

Whatever may happen, don't let them deny

If given a chance you can be as high,

Even oak is an orphan:

Its mother is cradle and father is sky" (Kekilbayuly, 1999) -words father is

sky, mother is a cradle can be considered as the image of the world in the poet's consciousness.

E.A.Kerimbayev states: "we should remember that the image of the universe is a synthetical unit of subjective and objective beginnings in person's worldview, as well as synthesis of individual, spiritual and 
cultural-historical hypostasis" (Kerimbayev, 1992). Z. M. Abdyrakhmanova considers the world as a concept: "If we systematize the world; world is a planet and space; world is a nature and its hazards (animals and plants); world is a social environment, world is a planet of people, world is a phenomenon of ideals (morality, esthetics, religion etc.) All in all, notion of the "world" is a the permanent concept in Kazakh culture" (Abdyrakhmanova, 2004).

Picture of the world should not be mistaken with the worldview, worldview is the philosophical concept, and linguistic picture of the world is a linguistic concept. Both of the concepts have the same root, but when the first covers very large area, the second one limited by language. According to I.Ergaly: "Worldview is the concept that signifies disparate relationship between person and the world that become the fundament to the spiritual relation to the world and covers it in general" (Ergali, 2003). Picture of the world in the poet's language often can be observed in metaphors. For example:

"Let people or smile walk on my face,

Let whole herd of horses, without slowing pace,

I'll make the world tremble right up to the base,

Let dust of their fear land on my space

Let dust of creation leave visible trace" (Kekilbayuly, 1999).

The main function of the conceptual system is to systematize and categorize complex national concepts by its content. However, we would like to remind that in Kazakh linguistics this issue has been addressed only recently, so the conceptual system and its components are still explored. Example:

"The window of shelter cannot be the door,

The ceiling is near to fall on the floor.

The wind of December howled and tore,

With shivering sound that wasn't heard before" (Kekilbayuly, 1999).

There is also another thing that lies in the fundamentals of cognitive metaphor - a cognitive model (example). A. B. Amirbekova considers that integral parts of the concept emerge from the close affinity between conceptual system and cognitive model. "In our opinion, the main pillar that shows the conceptual image of the world is a conceptual system. Conceptual system consists of external and internal structures. There internal structures are: frame, script, word picture, design and external structures are: word, phraseology, metaphor, sentence, phrase, metonymy and etc. While forming a conceptual system, internal structure of a consciousness grouped in a certain model. Cognitive model emerges with the help of symbol, image, prototype, etiquette, standard, associative and stereotypical units and inside signs in author's consciousness" (Amirbekova, 2006). G. Gizdatov studies its types by using experiments and claims: "overall, cognitive models do not appear with human when they were born. It is a result of person's individual experience and long time of humanity's development" (Gizdatov, 1999). G. E. Utebalieva, who addressed the issue of foreign language teaching, displays the communicative-cognitive type of the model and says that: "foreign language learning mechanism should be described as assemblage of all its components" (Utebalieva, 2008). Therefore, we can use the following example from the poet's work:

\section{"Honesty odd, lie is an even and trick is a twin,}

Life is not prominent, there darkness within.

When reaper will come, alone you will be,

In loneliness pay for your crimes and sin" (Kekilbayuly, 1999)

\section{Conclusion}

Thus, cognitive model is an example or structure that displays integral parts of the concept through different associative and symbolic signs.

From the cognitive point of view, all metaphorical models combines with each other, this is also based on denovative position. A. N. Baranov divides metaphors to formally combined and contextually combined. He also conjugates formally combined metaphors to internal and external. Internal combinations consist of connected denotative and unconnected denotative metaphors; external combinations are similar to the previous but rely to the context. Contextually combined metaphorical models are divided into 2: cognitive-semantically combined and ontologically combined which is concerned to the linguistic image of the universe (Baranov, 2003). A. Amirbekova displays with the drawings that in creating a concept, metaphor relies on semantics. For example, 
"in the metaphor "The lad is an eagle" S1 - lad - brave, courageous; S2 - eagle - strength, predator; F1 defender of the country, F2 - king of the birds" (Amirbekova, 2006). Metaphor has a special function in creation of a concept. E.g. A. Amirbekova writes: "metaphor serves as a depiction of the concept-building structural elements. Process of metaphor based on associative, stereotypical and symbolic concepts from person's experience. The simple function of the metaphor in building a concept is to change characteristic of the perceptive world and create a new background to the gestalt structure of the consciousness" (Amirbekova, 2006). V.N.Telia points: "Cognitive metaphors are metaphors that create and name abstract concepts" (Telia, 1988).

In poems of A.Kekilbay his national and psychological cognition can be observed. Though it's not a frequent phenomenon, we would like to show an example from the poet's work:

Red-tongued gambols from sunrise till dark .

Stone deaf believing he's leaving his mark,

"I know it, I see it" will the blind mice bark,

And rickets are trying to travel by spark,

Shorties feel giant saying "I'll make you stark",

Stutterers orate like they lead an ark (Kekilbayuly, 1999).

Here using the words with negative connotation such as: red-tongued, stone deaf, blind mice, rickets, shorties, stutterers poet state his point of view full of cognitive metaphors. In conclusion, to disclose the basis of cognitive metaphor formation, we need to conduct in-depth researches.

\section{References}

Abdyrakhmanova, J. M. (2004). Connection of language and worldview: On the basis of A. Kekilbayev's creativity. Almaty.

Amirbekova, A. B. (2006). Verbal features of conceptual poetical structuresi: on the poetry of M.Makatayev. Almaty.

Baranov, A. N. (2003). About the types of compatability of metaphorical models. Questions of linguistics, 2, 73-94.

Ergali, I. E. (2003). Philosophy as spiritual activity. Astana.

Gizdatov, G. G. (1999). Typology and dynamics of cognitive model in speech activity. Almaty.

Islam, A. (2004). Linguistic picture of the world in the context of national culture. Almaty.

Kekilbayuly, A. (1999). Dunie gapyl. Poems and drama. Almaty.

Kerimbayev, E. A. (1992). Ethno-cultural basis of nomination and functioning of Kazakh proper names. Almaty.

Maslova, V. A. (2007). Introduction to cognitive linguistics. Moscow: Nauka.

Orazalieva, E. (2007). Cognitive linguistics: formation and development. Almaty: An-Arys.

Pavilenis, N. I. (1983). Problems of meaning: Modern logical-functional linguistic analysis. Moscow.

Popova, Z. D., \& Sternin, I. A. (2007). Cognitive linguistics. Moscow: Vostok-Zapad.

Telia, V. N. (1988). Metaphor as model of meaning production and its expressive-estimated function. Moscow.

Utebalieva, G. E. (2008). Foreign language learning: communicative-cognitive model. Almaty.

Znakov, V. V. (1991). Understanding as a problem of psychology of thinking. Questions of psychology, 1, 22-23.

\section{Copyrights}

Copyright for this article is retained by the author(s), with first publication rights granted to the journal.

This is an open-access article distributed under the terms and conditions of the Creative Commons Attribution license (http://creativecommons.org/licenses/by/3.0/). 